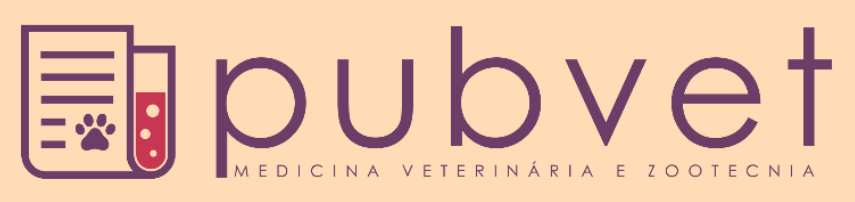

https://doi.org/10.31533/pubvet.v15n02a760.1-7

\title{
Avaliação da viabilidade técnica econômica da terminação de machos da raça Holandês no oeste de Santa Catarina
}

\author{
Eduarda Cristina Sparremberger ${ }^{1,2} 9$, Muriel Felipe Moras ${ }^{1}$, Vandrigo Danelli ${ }^{1}$, Ricardo Xavier \\ Rocha $^{3}$, José Francisco Manta Bragança ${ }^{4 *(9)}$ \\ ${ }^{1}$ Discente do curso de Medicina Veterinária, Universidade do Oeste de Santa Catarina, Faculdade de Medicina Veterinária - Xanxerê/Santa \\ Catarina, Brasil. ${ }^{2}$ Bolsista Uniedu \\ ${ }^{3}$ Médico Veterinário Empresa Agrifirm \\ ${ }^{4}$ Docente do curso de Medicina Veterinária, Universidade do Oeste de Santa Catarina, Faculdade de Medicina Veterinária - Xanxerê/Santa \\ Catarina, Brasil.*Autor para correspondência, Email: jose.branganca@unoesc.edu.br
}

Resumo. O objetivo desse estudo foi avaliar a viabilidade técnica econômica da terminação de machos leiteiros da raça Holandês, alimentados com dieta de alto grão. Ao todo, 24 animais, com idade média de 60 dias e peso médio de 40,3 quilos $(\mathrm{kg})$ foram desmamados e mantidos em confinamento até os 315 dias, quando foram abatidos em frigorifico comercial. Após o período de adaptação, a dieta composta $90 \%$ de milho grão inteiro e $10 \%$ Rumenature $^{\circledR}$ (Agrifirm) foi fornecida duas vezes ao dia em cochos lineares. O acesso a água e feno era irrestrito. Os animais foram pesados mensalmente e os pesos, bem como custos para produção foram anotados e tabelados. Os bezerros apresentaram ganho de peso médio diário de $1,314 \mathrm{~kg}$, peso médio de abate de $393,2 \mathrm{~kg}$ e rendimento de carcaça de $48,9 \%,(193,3 \mathrm{~kg})$. Até o momento do abate, houve um custo de produção individual de $\mathrm{R} \$$ $1.555,35$, com R $\$ 1.755,98$ de receita, oriunda do abate dos animais. Dessa forma, o lucro individual foi de $\mathrm{R} \$ 200,75$, demonstrando que a terminação de machos de origem leiteira pode tornar-se uma alternativa ao descarte, gerando uma segunda renda dentro das propriedades leiteiras e preenchendo um novo nicho de mercado.

Palavras-chave: Alto grão, bovinocultura, confinamento, rentabilidade

\section{Evaluation of the technical and economic viability of the termination of Holstein males in Western Santa Catarina}

\begin{abstract}
The objective of this study was to evaluate the technical-economic viability of finishing Holstein dairy cows, being fed a high grain diet. In all, 24 animals, with an average age of 60 days and an average weight of $40.3 \mathrm{kilos}(\mathrm{kg})$ were weaned and kept in confinement until 315 days, when they were slaughtered in a commercial fridge. After the adaptation period, the diet composed of $90 \%$ whole grain corn and $10 \%$ Rumenature $^{\circledR}$ (Agrifirm) was provided twice a day in linear troughs. Access to water and hay was unrestricted. The animals were weighed monthly and the weights, as well as production costs, were noted and tabulated. Calves had an average daily weight gain of $1.314 \mathrm{~kg}$, an average slaughter weight of $393.2 \mathrm{~kg}$, and a carcass yield of $48.9 \%,(193.3 \mathrm{~kg})$. Up until the time of slaughter, there was an individual production cost of $R \$ 1,555,35$, with $R \$$ $1,755,98$ in revenue, resulting from the slaughter of the animals. Thus, the individual profit was R \$200.75, demonstrating that the termination of males of dairy origin can become an alternative to disposal, generating a second income within the dairy properties and filling a new market niche.
\end{abstract}

Keywords: High grain, cattle farming confinement, profitability 


\section{Evaluación de la viabilidad técnica y económica de la engorda de machos Holstein en el oeste de Santa Catarina}

Resumen. El objetivo de este estudio fue evaluar la viabilidad técnica y económica de terminar machos lecheros Holstein alimentados con una dieta alta en granos. En total, 24 animales, con una edad promedio de 60 días y un peso promedio de $40.3 \mathrm{kilos}(\mathrm{kg})$ fueron destetados y mantenidos en confinamiento hasta 315 días, cuando fueron sacrificados en un frigorífico comercial. Después del período de adaptación, la dieta compuesta de $90 \%$ de maíz integral y $10 \%$ de Rumenature ${ }^{\circledR}$ (Agrifirm) fue suministrada dos veces al día en comederos lineales. El acceso al agua y al heno no tenía restricciones. Se pesaron los animales mensualmente y se anotaron y tabularon los pesos, así como los costos de producción. Los terneros tuvieron un aumento de peso diario promedio de $1.314 \mathrm{~kg}$, un peso promedio de sacrificio de $393.2 \mathrm{~kg}$ y un rendimiento de canal de $48.9 \%$ (193.3 kg). Hasta el momento del sacrificio, había un costo de producción individual de R \$ 1.555,35, con R \$1.755,98 en ingresos, resultantes de la matanza de los animales. Por lo tanto, la ganancia individual fue de R \$200,75, lo que demuestra que la terminación de los machos de origen lácteo puede convertirse en una alternativa a la eliminación, generando un segundo ingreso dentro de las propiedades lácteas y llenando un nuevo nicho de mercado.

Palabras clave: Alto grano, bovinocultura, confinamiento, rentabilidad

\section{Introdução}

A cadeia produtiva do leite é uma das atividades mais rentáveis no agronegócio, envolvendo cerca de 1,3 milhões de propriedades, em $99 \%$ das cidades brasileiras e, quatro milhões de trabalhadores (IBGE, 2017). Estima-se que em 2026, a população brasileira chegue a 219 milhões de pessoas, gerando aumento na demanda de leite, com uma projeção de consumo de 37 bilhões de litros, mantendo nível de consumo atual, 170 litros de leite/habitante/ano (Zoccal, 2016). Assim, o mercado leiteiro brasileiro cresceu 78\% nos últimos cinco anos (EMBRAPA, 2018), destaque para a região sul que alcançou a maior produção leiteira do Brasil, perfazendo $34,7 \%$ do total de leite produzido no país (IBGE, 2017). No oeste de Santa Catarina, está localizada a maior bacia leiteira da região, perfazendo $25 \%$ da produção (EMBRAPA, 2018).

Da mesma forma, o mercado de carne brasileiro está em plena expansão, tendo exportado 1,64 milhões de toneladas em 2018 (ABIEC, 2019), tornando-se o maior exportador mundial e abrindo novos mercados paralelamente (Semchechem, 2019). Em comparativo entre o primeiro trimestre de 2018 e 2019, o país exportou 2,6\% toneladas liquidas de carne a mais, negociando com ao menos 11 países (Conab, 2019). Levando-se em conta que o Brasil é um país em expansão, bem como a demanda por lácteos e carne está em constante alta, a perspectiva é de crescimento para ambos os setores (Semchechem, 2019).

Neiva et al. (2015), estimam que nasçam cerca de dez milhões de machos de raças leiteiras anualmente no Brasil. Ainda, destacam que tradicionalmente esses animais são abatidos em idade terna por não apresentarem perspectivas comerciais futuras para as fazendas. Caso contrário, usualmente são criados em pastagens de baixa qualidade, sem aporte nutricional adequado, demorando a atingir o peso de abate, culminando em baixo rendimento de carcaça e inviabilizando sua terminação. Em estudo realizado no sul do Brasil, Hötzel et al. (2014) relataram que 51\% dos produtores criam, vendem ou doam os machos nascidos, enquanto $35 \%$ abatem todos os nascidos e $14 \%$ os abatem apenas quando não possuem mais local disponível para alojá-los.

Todavia, países com uma atividade leiteira desenvolvida, os bezerros são aproveitados para a engorda, caracterizando uma parcela importante do setor produtivo, representando aproximadamente 20\% (Mousquer et al., 2013). Na Europa e América do Norte, são uma segunda fonte de renda dentro das propriedades (Resende \& Signoretti, 2005; Prado et al., 2014). Comumente, são abatidos como "vitelos", uma carne bastante aceita nos países europeus, sendo criados apenas com dieta líquida (leite ou composto lácteo), o que mantem a cor de sua carne mais clara e com máximo 20 semanas de idade (Mousquer et al., 2013). 
No Brasil, a inciativa que ganhou maior destaque foi a de Caldas (2003), denominada "Vitelo Tropical". Devido ao alto custo dos produtos lácteos, a inclusão de grãos torna-se uma opção (Feijó et al., 2001). Assim sendo, a proposta consistia em alimentar os bezerros com dietas de alto grão do desmame até os cinco meses ou peso de 170 a 220 quilos $(\mathrm{kg})$. Alternativas foram elaboradas, como a produção de vitelos mestiços, caso do "Vitelo Modificado". Nesse sistema, machos híbridos de raças leiteiras com zebuínas são abatidos até os 10 meses de idade e com peso de $300 \mathrm{~kg}$ (Brito, 2014). Ao terminarem de forma precoce e com qualidade os bezerros leiteiros e investirem em publicidade, um novo nicho de mercado poderia estar sendo preenchido, garantindo a rentabilidade da atividade que poderá servir como renda extra dentro das propriedades leiteiras (Santos, 2013).

Dessa forma, objetivou-se buscar um protocolo para a criação dos machos leiteiros da bacia leiteira do Oeste de Santa Catarina. Para tanto, investigou-se alimentos e manejos que viabilizem técnica e economicamente essa atividade dentro das propriedades, ou em centros de recria e engorda desses animais distribuídos em várias regiões do Estado.

\section{Material e métodos}

O presente estudo foi realizado em uma fazenda da região Oeste de Santa Catarina, no período de junho de 2019 a junho de 2020. Durante o período, realizou-se visitas mensais para anotação de dados e pesagem dos bezerros. Foram selecionados 24 bezerros com peso médio de 40,35 $\mathrm{kg}$ de peso vivo (PV) e cerca de 60 dias de vida. Eles foram alojados em galpão coberto com cochos e bebedouros dispostos lateralmente e acesso a área externa. $\mathrm{O}$ arrazoamento foi realizado duas vezes ao dia. $\mathrm{O}$ abate dos animais ocorreu em frigorifico comercial, seguindo a linha normal de abate.

$\mathrm{Na}$ fase de aleitamento, os animais receberam feno, substituto lácteo e ração comercial pré inicial durante 50 dias. Após, iniciou-se a fase de adaptação a dieta de terminação, com inclusão de $75,00 \%$ de ração comercial pré inicial e 30,00\% alto grão, com milho moído inteiro. A substituição ocorreu gradativamente até os animais passarem a consumir $15,00 \%$ de núcleo peletizado Rumenature ${ }^{\circledR}$ (Agrifirm) e 85,00\% de milho em forma de grão. Nesta fase, os animais permaneceram dos 61 aos 130 dias de idade, e peso aproximado de $143 \mathrm{~kg}$ de PV. Na fase subsequente, os animais passaram a receber $12,50 \%$ de Rumenature ${ }^{\circledR}$ e $87,50 \%$ de milho grão inteiro, sendo alimentados até o peso aproximado de $243 \mathrm{~kg}$ na idade de 210 dias. Na fase de terminação, forneceu-se $10,00 \%$ de Rumenature ${ }^{\circledR}$ e $90,00 \%$ de milho grão inteiro, até os animais atingirem aproximadamente $415 \mathrm{~kg}$ de PV aos 315 dias. O feno foi fornecido à vontade, bem como acesso a água.

Os dados provenientes das pesagens e das anotações dos gastos foram tabulados e posteriormente analisados. Para determinar despesas para a terminação foram determinados custo operacional total (valor necessário para que a operação ocorra), custo operacional variável (insumos, alimentação, medicamentos, manutenção, mão de obra, serviços), custos operacionais fixos (benfeitorias, máquinas, equipamentos, consultorias fixas, impostos e taxas fixas, considerando sua depreciação quando necessário) e custos operacionais totais (soma dos custos operacionais variáveis mais custos operacionais fixos). Este trabalho foi aprovado pelo Comitê de Ética no uso de Animais (CEUA) da Unoesc com o protocolo 73/2019.

\section{Resultados e discussão}

A fase de aleitamento, adaptação, inicial, crescimento e terminação duraram respectivamente, em média, 50, 10, 69, 197 e 104 dias. Santos (2013) pré estipulou peso de abate de cerca de $200 \mathrm{~kg}$, demonstrando que para atingir tal meta os animais levaram 221 e 153 dias, para bezerros criados em pastagens e confinamentos, respectivamente, destacando que tal diferença ocorre pelo ganho de peso diário (GPD). Em estudo similar, com peso de abate pré estipulado em $300 \mathrm{~kg}$, os animais permaneceram em média 176 dias em confinamento (Aguiar et al., 2018).

Os animais do estudo permaneceram em confinamento por 10 meses, com média de ganho de peso diário de $1,314 \mathrm{~kg}$. O resultado aproxima-se do encontrado por Neiva et al. (2015). avaliando a eficiência de dietas a base de milho grão inteiro e suplemento proteico, mineral e energético, sob a terminação de bovinos de origem leiteira super jovem. Os autores estimaram o ganho de peso em 1,220 kg aos 10 meses de idade, resultado considerado por eles excelente, já que a média considera o GPD a partir dos 
90 dias. No presente estudo, as médias correspondem ao GPD a partir de 60 dias. Santos (2013), encontrou GPD de $0,941 \mathrm{~kg}$ para animais em confinamento, contra $0,710 \mathrm{~kg} / \mathrm{dia}$ para animais mantidos em pastagem, sendo as médias computadas a partir dos 60 dias de idade. $\mathrm{O}$ desfecho assemelha-se ao GPD de raças de corte quando abatidas de forma precoce, aos 15 meses de idade, ou super precoce, aos 27 meses. O GPD para essas categorias é de aproximadamente 1,004 e 1,351 (Gottschall et al., 2009).

Neste trabalho os animais obtiveram acesso irrestrito ao feno. Turgeon et al. (2010), defendem que a utilização de volumoso melhora a conversão alimentar e a disponibilidade de energia liquida para ganho de peso, destacando, porém, uma diminuição do GPD e consumo de matéria seca, fato não corroborado no presente estudo. Em contrapartida, em análise de diferentes inclusões de concentrado em dietas a base de silagem de milho, notou-se que quanto maior a adição de concentrado, linearmente ocorre aumento na eficiência alimentar e ruminação, acarretando alto GPD (Missio et al., 2010).

No presente estudo os animais receberam dieta alto grão, sendo composta, na fase de terminação, $90 \%$ por milhão grão inteiro e $10 \%$ por Rumenature ${ }^{\circledR}$. Avaliando o desempenho de bois Nelore e oriundos do cruzamento Nelore x Brahman, terminados com três diferentes dietas, sendo elas a base de silagem de milho e ração concentrada, apenas núcleo peletizado e grão inteiro e núcleo peletizado, Mandarino et al. (2013), concluíram que a utilização de silagem e ração concentrada geraram maior ganho de peso e lucro, porém todas as alternativas mostraram-se rentáveis, não tendo as raças influenciado no desempenho, acordando com os resultados deste trabalho.

Optou-se por manter os bezerros em confinamento, tendo em vista o pouco espaço disponível para esta categoria dentro das propriedades leiteiras, bem como facilidade de manejo. Dias et al. (2016), reitera que o confinamento pode ser uma alternativa viável para garantir maior GPD e uniformidade do lote, alertando aos cuidados que se deve ter com o os custos de produção. O referido trabalho utilizou proposta similar a deste estudo, com inclusão de $85 \%$ de milho inteiro e $15 \%$ de núcleo peletizado, garantindo GPD de 1,290 kg e 1,500 kg, para animais inteiros e castrados, respectivamente.

Em relação ao peso médio de abate obtido, este foi de $393,2 \mathrm{~kg}$ e um rendimento de carcaça de $48,9 \%$. Tais resultados assemelham-se ao esperado para raças estritamente de corte. Ao abate, animais com PV médio de 524,35 e 413,20 kg, das raças Canchim e Nelore respectivamente, apresentaram rendimento de carcaça de 55,42 e 58,75\% (Rubiano et al., 2009). Cavalcante (2017), realizou uma análise meta-analítica da qualidade quantitativa da carcaça de bovinos em frigorífico comercial. No referido trabalho, identificou PV médio de $352,36 \mathrm{~kg}$, com peso de carcaça médio de $260 \mathrm{~kg}$. Os valores corroboram com os achados de Silva et al. (2018), utilizando animais Bos indicus. Com peso de abate médio de $389 \mathrm{~kg}$, a carcaça pesou $206 \mathrm{~kg}$, totalizando um rendimento de $53 \%$. Em nosso estudo, o peso de carcaça foi de 193,3 kg. Os montantes diferem entre si possivelmente em decorrência da especialidade das raças. Segundo Rubiano et al. (2009), as raças taurinas possuem rendimento de carcaça ligeiramente inferior as raças zebuínas.

$\mathrm{Na}$ Tabela 1 estão descritas as despesas para a terminação. O custo individual até o momento do abate foi de R\$1.555,35. Mandarino et al. (2013), comparando objetivamente os gastos para a terminação de gado nelore em sistema semi-intensivo, nos anos de 2012, 2013 e 2014, obteve como custo total $\mathrm{R} \$ 1.249,08, \mathrm{R} \$ 1.482,75$ e $\mathrm{R} \$ 1.756,90$, respectivamente. Por se tratar de gado de corte, a aquisição do bezerro foi o maior custo. No presente estudo, o maior custo foi com a dieta da fase de terminação, totalizando $\mathrm{R} \$ 833,09$ por cabeça. $\mathrm{O}$ valor aproxima-se pelo estipulado por Neiva et al. (2015), considerando o preço do milho R \$ 0,50. Tendo em vista o abate de animais com 10 meses, alimentados à vontade, os autores determinaram um custo de aproximadamente $\mathrm{R} \$ 694,83$. Nascimento et al. (2017), compararam os custos de produção do sistema intensivo e semi intensivo e, corroborando com o presente estudo, identificou que o maior custo de produção se refere a alimentação.

Medicamentos, incluindo anti parasitários, vacinas e antibióticos, correspondeu a 3,07\% das despesas. O encontrado ficou acima do citado por Lopes \& Carvalho (2006), dos quais determinaram que os gastos com sanidade para a produção de 500 cabeças por 100 dias em confinamento, é de aproximadamente $\mathrm{R} \$ 1.160,28$, correspondendo a $0,47 \%$ do desembolso. Invariavelmente este custo vem aumentando dentro das propriedades devido a inflação que tais produtos sofreram nos últimos anos (Mandarino et al., 2013). 
Tabela 1. Custos da terminação de bovinos de origem leiteira em dieta de Alto Grão.

\begin{tabular}{ll}
\hline & Resumo das Despesas \\
\hline Produto & Valor \\
\hline Leite em Pó e Ração Pré Inicial/Inicial & $\mathrm{R} \$ 7.332,35$ \\
Compra Matéria Prima (bezerros, feno) & $\mathrm{R} \$ 3.974,40$ \\
Ração Inicial & $\mathrm{R} \$ 3.260,18$ \\
Medicamentos & $\mathrm{R} \$ 1.208,60$ \\
Alto Grão & $\mathrm{R} \$ 19.994,90$ \\
Total & $\mathrm{R} \$ 35.770,43$ \\
Total por cabeça & $\mathrm{R} \$ 1.555,35$ \\
\hline
\end{tabular}

Quanto as receitas, estas estão descritas na Tabela 2. As receitas correspondem ao abate dos animais, sendo que houve a morte de um bezerro na fase final. O programa de terminação gerou $\mathrm{R} \$ 1.755,98$ por cabeça, valor similar ao levantado hipoteticamente por Neiva et al. (2015), considerando a arroba (@) do boi $\mathrm{R} \$ 120,00$. No ano de 2012, a @ do boi estava $\mathrm{R} \$ 87,00$, com isso, animais com rendimento de carcaça de $53 \%$, correspondiam a uma receita de $\mathrm{R} \$ 1.598,19$, sendo demonstrado aumentos subsequentes no preço recebido pelo produtor (Mandarino et al., 2013).

Tabela 2. Receitas da terminação de bovinos de origem leiteira em dieta de Alto Grão.

\begin{tabular}{|c|c|c|c|c|}
\hline \multicolumn{5}{|c|}{ Resumo das Receitas } \\
\hline & $\mathrm{N}^{\circ}$ de cabeças & Peso Médio Carcaça $(\mathrm{kg})$ & Total de $\mathrm{Kg}$ & Valor Recebido \\
\hline & 23 & 191,17 & $4.397,7$ & $\mathrm{R} \$ 41.338,38$ \\
\hline Fundo Rural & & & & - R\$900,00 \\
\hline Total & & & & $\mathrm{R} \$ 40.387,60$ \\
\hline Total por cabeça & & & & $\mathrm{R} \$ 1.775,98$ \\
\hline
\end{tabular}

Já em relação aos lucros, encontram-se descritos na Tabela 3. O lucro obtido por cabeça foi de $\mathrm{R} \$$ 200,75, valor similar, porém inferior ao achado por Souza \& Melz (2014), que foi de $\mathrm{R} \$ 298,00$. Cruz \& Guzatti (2019), avaliaram o lucro bruto de uma propriedade em $\mathrm{R} \$ 638,57$ por animal, resultado semelhante ao descrito por Franco et al. (2010), que foi de R \$536,22. O estudo porem foi realizado em sistema extensivo, o que demanda menor investimentos e custo com suplementação, porem maior tempo até a terminação.

Tabela 3. Lucros da terminação de bezerros de origem leiteira em dieta de Alto Grão.

\begin{tabular}{lcc}
\hline & \multicolumn{2}{c}{ Resultados da Operação } \\
\hline & Por Cabeça & Por Lote \\
\cline { 2 - 3 } Total de Despesas & $\mathrm{R} \$ 1.555,24$ & $\mathrm{R} \$ 35.770,43$ \\
Total de Receitas & $\mathrm{R} \$ 1.755,98$ & $\mathrm{R} \$ 40.387,60$ \\
Lucro & $\mathrm{R} \$ 200,75$ & $\mathrm{R} \$ 4.617,17$ \\
\hline
\end{tabular}

Com o passar dos anos, questões relacionadas ao bem-estar animal têm sido cada vez mais debatidas e até questionadas pela sociedade, bem como a possibilidade de produção de carne com qualidade e terminação precoce dos animais, aumentando a renda das propriedades e visando menor produção de metano. Dessa forma, a terminação de machos leiteiros poderá tornar-se uma opção interessante para o produtor, tendo em vista a qualidade da carne produzida e a rentabilidade econômica.

\section{Agradecimentos}

Ao UNIEDU pelo auxílio bolsista e à empresa Agrifirm Brasil pelo fornecimento do suplemento alimentar.

\section{Referências}

ABIEC. (2019). Associação Brasileira das Indústrias Exportadoras de Carnes. Exportações Brasileiras de Carne Bovina - Brazilian Beef Exports (P. e A. Ministério da Agricultura (ed.)). Governo brasileiro. 
Aguiar, G. S. A., Silva, F. E. G., Victor, J., Souza, P., Cunha, G. S. P., \& Gonçalves, L. M. (2018). Aproveitamento de machos de origem leiteira para produção de carne no norte de Minas Gerais. CONGRESSO BRASILEIRO DE ZOOTECNIA, $28^{a}$ Edição. Goiânia - GO. Anais..., 2478-2483.

Brito, R. F. (2014). Utilização de dietas com grão de milho inteiro para produção de Vitelos modificados. 90f. Dissertação (Mestrado em Ciência Animal Tropical)-Universidade Federal do Tocantins, Araguaína.

Caldas, F. (2003). Vitelo: opção de ganho na exploração leiteira. Revista Balde Branco, 38(461), 3640.

Cavalcante, A. S. A. (2017). Estudo meta-analítico de características relacionadas à qualidade da carne e da carcaça em bovinos [Dissertação (Mestrado em Ciência Animal) - Universidade Federal de Goiás, Goiânia]. http://repositorio.bc.ufg.br/tede/handle/tede/7391\%0A

Conab. (2019). Indicadores da Agropecuária. In Companhia Nacional de Abastecimento. https://www.conab.gov.br/indicadores-da-agropecuaria

Cruz, A. M., \& Guzatti, N. C. (2019). Custos e lucratividade na produção de bovinos no sistema de pecúaria extensiva, no município de Denise-MT. Revista UNEMAT de Contabilidade, 8(16), 155179. https://doi.org/10.30681/ruc.v8i16.3434

Dias, A. M., Oliveira, L. B., Ítavo, L. C. V., Mateus, R. G., Gomes, E. N. O., Coca, F. O. C. G., Ítavo, C. C. B. F., Nogueira, É., Menezes, B. B., \& Mateus, R. G. (2016). Terminação de novilhos Nelore, castrados e não castrados, em confinamento com dieta alto grão. Revista Brasileira de Saúde e Produção Animal, 17(1).

EMBRAPA. (2018). Anuário do leite: Indicadores, tendências e oportunidades para quem vive no setor leiteiro. Empresa Brasileira de Pesquisa Agropecuária, 116. https://www.embrapa.br/busca-depublicacoes/-/publicacao/1094149/anuario-leite-2018-indicadores-tendencias-e-oportunidadespara-quem-vive-no-setor-leiteiro

Feijó, G. L. D., Costa, F. P., \& Feijó, R. M. B. (2001). Carne de vitelão: estudo exploratório de um mercado potencial. Embrapa Gado de Corte Campo Grande.

Franco, C., Moura, B. S. C., \& Dias, P. B. (2010). Transações e estruturas de governança na cadeia produtiva da avicultura de corte em Mato Grosso. Revista ADMPG, 3(2). https://revistas.apps.uepg.br/index.php/admpg/article/view/13941

Gottschall, C. S., Canellas, L. C., Marques, P. R., \& Bittencour, H. R. (2009). Relações entre idade, peso, ganho médio diário e tempo médio de permanência de novilhos de corte confinados para abate aos 15 ou 27 meses de idade. Semina: Ciências Agrárias, 30(3), 717-726.

Hötzel, M. J., Longo, C., Balcão, L. F., Cardoso, C. S., \& Costa, J. H. C. (2014). A Survey of Management Practices That Influence Performance and Welfare of Dairy Calves Reared in Southern Brazil. PLoS ONE, 9(12), e114995. https://doi.org/10.1371/journal.pone.0114995

IBGE. (2017). Produção da Pecuária Municipal - PPM. Instituto Brasileiro de Geografia e Estatística. https://www.ibge.gov.br/estatisticasnovoportal/economicas/agriculturaepecuaria/9107producaodapecuariamunicipal.html?\&t=resultados

Lopes, M. A., \& Carvalho, F. M. (2006). Custo de produção de gado de corte: uma ferramenta de suporte ao pecuarista. Jornada Técnica Em Sistemas de Produção de Bovinos de Corte e Cadeia Produtiva: Tecnologia, Gestão e Mercado, 1.

Mandarino, R. A., Barbosa, F. A., Cabral Filho, S. L. S., Lobo, C. F., Silva, I. S., Oliveira, R. V., Diogo, J. M. S., \& Guimarães Júnior, R. (2013). Desempenho produtivo e econômico do confinamento de bovinos zebuínos alimentados com três dietas de alto concentrado. Arquivo Brasileiro de Medicina Veterinária e Zootecnia, 65(5), 1463-1471. https://doi.org/10.1590/S0102-09352013000500027

Missio, R. L., Brondani, I. L., Alves Filho, D. C., Silveira, M. F., Freitas, L. S., \& Restle, J. (2010). Comportamento ingestivo de tourinhos terminados em confinamento, alimentados com diferentes níveis de concentrado na dieta. Revista Brasileira de Zootecnia, 39(7), 1571-1578. https://doi.org/10.1590/S1516-35982010000700025.

Mousquer, C. J., Hoffmann, A., Silva, M. R., Fernandes, G. A., Fernandes, F. F. D., Silva Filho, A. S., Castro, W. J. R., \& Ferreira, V. B. (2013). Benefícios do uso de animais geneticamente superiores 
para o aumento da eficiência produtiva. PUBVET, 7, 2088-2188.

Nascimento, M. F. A., Taveira, R. Z., Carvalho, F. E., Amaral, A. G., Silva, R. M., \& Campos, J. C. D. (2017). Viabilidade econômica de dois sistemas de produção de bovinos de corte. Revista Espacios, 38(37), 10-25.

Neiva, J. N. M. ., Cutrim, D., Maciel, R. P., Santana, A. E. ., Neiva, A. C. G. R. N., \& Restle, J. (2015). Aproveitamento de machos de origem leiteira para produção de carne. In: SIMLEITE, V, 2015, Viçosa-MG. Anais..., 196-215.

Prado, I. N., Campo, M. M., Muela, E., Valero M. V., Catalan, O., Olleta, J. L. \& Sañudo, C. (2014). Effects of castration age, dietary protein level and lysine/methionine ratio on animal performance, carcass and meat quality of Friesian steers intensively reared. Animal, 8(9),1561-1568

Resende, F. D., \& Signoretti, R. D. (2005). Vitelo: sistema de produção de carne de vitelo. Apta Regional, Polo Regional de Desenvolvimento Tecnológico Dos Agronegócios Da Alta Mogiana.

Rubiano, G. A. G., Arrigoni, M. D. B., Martins, C. L., Rodrigues, É., Gonçalves, H. C., \& Angerami, C. N. (2009). Desempenho, características de carcaça e qualidade da carne de bovinos superprecoces das raças Canchim, Nelore e seus mestiços. Revista Brasileira de Zootecnia, 38(12), 2490-2498. https://doi.org/10.1590/S1516-35982009001200027

Santos, P. V. (2013). Sistemas de terminação e pesos de abate de bovinos leiteiros visando à produção de carne de vitelão. Universidade Tecnológica Federal do Paraná.

Semchechem, R. (2019). Análise de índices produtivos e econômicos de bovinocultura de corte no brasil. Dissertação - Mestre em Saúde e Produção de Ruminantes, UNOPAR, Arapongas - Paraná.

Silva, E. S., Barcelos, M. P., Souza, S. L., Araújo, J. A., Oliveira, A. B., \& Barrero, R. P. (2018). Rendimento de carcaça de bovinos de classes sexuais oriundos de um rebanho comercial abatidos com peso semelhante. Congresso Brasileiro de Zootecnia, 28, 1-4.

Souza, R. N. S., \& Melz, L. J. (2014). Gestão de custos aplicada à bovinocultura de corte: o caso da fazenda paraíso em Juina-MT. Revista UNEMAT de Contabilidade, 3(5). https://doi.org/10.30681/ruc.v3i5.294

Turgeon, O. A., Szasz, J. I., Koers, W. C., Davis, M. S., \& Vander Pol, K. J. (2010). Manipulating grain processing method and roughage level to improve feed efficiency in feedlot cattle. Journal of Animal Science, 88(1), 284-295. https://doi.org/10.2527/jas.2009-1859

Zoccal, R. (2016). Alguns números do leite. Revista Balde Branco. Disponível Em: Http://Www. Baldebranco. Com. Br/Alguns-Numeros-Do-Leitel. Acesso Em, 29, 12-16.

Histórico do artigo:

Recebido: 2 de agosto de 2020 . Aprovado: 28 de agosto de 2020 . Disponível online: 27 de dezembro de 2020.
Licenciamento: Este artigo é publicado na modalidade Acesso Aberto sob a licença Creative Commons Atribuição 4.0 (CC-BY 4.0), a qual permite uso irrestrito, distribuição, reprodução em qualquer meio, desde que o autor e a fonte sejam devidamente creditados. 